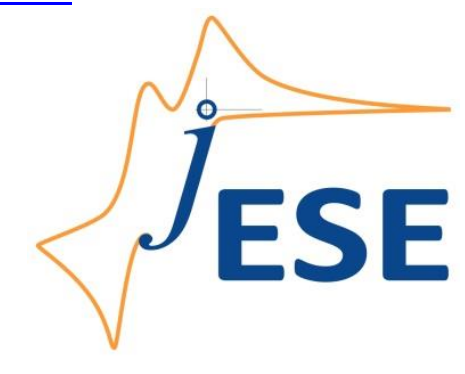

Open Access : : ISSN 1847-9286

www.jESE-online.org

Original scientific paper

\title{
Influence of supporting electrolyte on electrochemical formati- on of copper nanoparticles and their electrocatalytic properties
}

\author{
Noelia Zurita and Silvana G. García \\ Instituto de Ingeniería Electroquímica y Corrosión (INIEC), Departamento de Ingeniería \\ Química, Universidad Nacional del Sur, Av. Alem 1253, (8000) Bahía Blanca, Argentina \\ Corresponding authors: ${ }^{\bowtie}$ sgarcia@criba.edu.ar; Tel.: +54-9-291-4595100-3614
}

Received: August 11, 2021; Accepted: November 5, 2021; Published: November 22, 2021

\begin{abstract}
Comparative analysis of copper nanoparticles (CUNPs) obtained by electrodeposition on highly oriented pyrolytic graphite (HOPG) substrates from different supporting electrolytes containing sulphate anions, was performed. Voltammetric results indicated that $\mathrm{Cu}$ electrodeposition follows a diffusion-controlled nucleation and crystal growth model for three solutions studied $\left(\mathrm{Na}_{2} \mathrm{SO}_{4}, \mathrm{H}_{2} \mathrm{SO}_{4}\right.$ and $\left.\mathrm{Na}_{2} \mathrm{SO}_{4}+\mathrm{H}_{2} \mathrm{SO}_{4}\right)$. $\mathrm{Na}_{2} \mathrm{SO}_{4}$ solution was most effective because the copper reduction occurs at the most positive potential value, reaching the highest current density. Analysis of potentiostatic current transients revealed that the process can be described predominantly by a model involving a 3D-progressive nucleation mechanism, which was corroborated by scanning electron microscopy (SEM) analysis. SEM images showed a high density of hemispherical shaped Cu particles of different sizes (mostly between 80-150 nm), randomly distributed on the HOPG surface for $\mathrm{Na}_{2} \mathrm{SO}_{4}$ electrolyte solution. In the presence of $\mathrm{H}_{2} \mathrm{SO}_{4}$, the size dispersion decreased, resulting in particles with greater diameters (up to $339 \mathrm{~nm}$ ). The electrolyte solution with $\mathrm{Na}_{2} \mathrm{SO}_{4}+\mathrm{H}_{2} \mathrm{SO}_{4}$ revealed lower particle density with a considerable crystal size dispersion, where very small crystallites are prevailing. Cyclic voltammetry was used to evaluate qualitatively the catalytic activity of CuNPs deposited from three electrolyte solutions towards the nitrate reduction reaction. An enhanced catalytic effect was obtained when copper particles were prepared from either $\mathrm{Na}_{2} \mathrm{SO}_{4}$ or $\mathrm{H}_{2} \mathrm{SO}_{4}$ supporting electrolyte.
\end{abstract}

Keywords

Copper nanocrystals; electrodeposition; plating solution; highly oriented pyrolytic graphite (HOPG); nitrate reduction

\section{Introduction}

Recent studies have reported that supported copper nanostructures, in addition to being suitable for a wide range of applications (nanoelectronics [1], biosensing [2,3], optoelectronics [4], etc.), show excellent results as electrocatalyst material for different reactions, in particular those of 
environmental interest [5-8]. Nitrate ions are one of the chemical species that can be potentially dangerous for human health if their concentration in drinking water and food exceeds the upper limit allowed, as indicated by the World Health Association [9]. Therefore, there is a high necessity for nitrate ions to be detected and quantified. The detrimental effect of nitrate ions comes mainly from nitrogen-based fertilizers contaminating drinking water supplies, and their removal or reduction has gained special attention.

The ability of copper nanostructures as an electrocatalyst material for nitrate reduction has already been studied by several authors [10-12]. In particular, the influence of structural properties of nanoparticles has been analyzed on the reaction performance [13-15]. It has been demonstrated that the final properties of metal nanoparticles are strongly dependent on their surface morphology, which is essentially related to the selected preparation method. The electrodeposition is one of the most used preparation methods because it presents additional advantages. The main assets are simplicity and the possibility of working at room temperature and pressure. In addition, this method allows the kinetic process control and, consequently, the size of particles and the amount of formed deposit.

As stated above, the morphological features of deposits have a significant influence on their electrocatalytic properties. It is well known that variations of the plating solution composition and $\mathrm{pH}$ can influence the deposit morphology. Therefore, it is necessary to relate the operating conditions to the shape, size, and distribution of produced nanoparticles.

Previous works addressing the electrodeposition of copper nanoparticles on carbonaceous substrates, have analyzed the influence of some parameters of the electrochemical process on structural features of the deposit $[16,17]$. In particular, it was found that the $\mathrm{pH}$ and concentration of $\mathrm{CuSO}_{4}$ solution have a remarkable effect on the texture and population density of deposited nanostructures the use of $\mathrm{Na}_{2} \mathrm{SO}_{4}$ supporting electrolyte. For the latter, an intriguing behavior was reported, which deserves a detailed study [18].

On the other hand, the effect of anions present in the electrolytic solution has been analyzed by several authors $[19,20]$. González et al. [19] have investigated $\mathrm{Cu}^{+}$intermediate species formed during copper electrodeposition process and demonstrated that in the presence of $\mathrm{NO}_{3}{ }^{-}$ions, the value of the reduction peak current increases because this anion is catalytically reduced on Cu nanoparticles freshly electrodeposited on a glassy carbon electrode. Presence of $\mathrm{SO}_{4}{ }^{2-}$ anions in the plating solution does not interfere with the current measurement of the copper reduction, but they are adsorbed considerably, preventing the discharge of $\mathrm{Cu}^{+}$ions. For $\mathrm{ClO}_{4}{ }^{-}$ions, adsorption is negligible; therefore, a reduction peak current higher than from $\mathrm{SO}_{4}{ }^{2--}$ anions is evidenced. These studies were carried out at $\mathrm{pH} 3$ with a higher $\mathrm{Cu}^{2+}$ concentration than in the present study. Bélanger et al. [20] analyzed the copper electrodeposition on highly oriented pyrolytic graphite (HOPG) substrates using two different copper salts $\left(\mathrm{CuSO}_{4}\right.$ and $\left.\mathrm{Cu}\left(\mathrm{NO}_{3}\right)_{2}\right)$ in $1.8 \mathrm{M} \mathrm{H}_{2} \mathrm{SO}_{4}$ aqueous solution and demonstrated that the deposition of copper in the presence of $\mathrm{CuSO}_{4}$ induced the co-deposition of sulfate anions.

In the present work, a comparative analysis of the initial stages of copper electrodeposition on HOPG from different supporting electrolytes containing $\mathrm{SO}_{4}{ }^{2-}$ anions $\left(\mathrm{Na}_{2} \mathrm{SO}_{4}, \mathrm{H}_{2} \mathrm{SO}_{4}\right.$ and $\mathrm{Na}_{2} \mathrm{SO}_{4}+$ $\mathrm{H}_{2} \mathrm{SO}_{4}$ ) has been carried out to increase the understanding of the nucleation and growth of copper particles and their electrocatalytic properties. The electrodeposition process is studied using conventional electrochemical techniques (cyclic voltammetry and chronoamperometry), and the copper deposits are characterized by scanning electron microscopy (SEM) with energy-dispersive Xray spectroscopy (EDX). The catalytic effect for the reduction of nitrate anions in $\mathrm{NaNO}_{3}+\mathrm{Na}_{2} \mathrm{SO}_{4}$ solution has been qualitatively evaluated by voltammetric measurements for CuNPs deposited from three different sulphate-containing media. 


\section{Experimental}

The solutions used in this work for metal deposition were prepared with supra pure chemicals (E. Merck, Darmstadt, Germany) and tri-distilled water. The supporting electrolytes added to $1 \mathrm{mM} \mathrm{CuSO}_{4}$ solution were $0.1 \mathrm{M} \mathrm{Na}_{2} \mathrm{SO}_{4}, 0.1 \mathrm{M} \mathrm{H}_{2} \mathrm{SO}_{4}$ and $0.1 \mathrm{M} \mathrm{Na}_{2} \mathrm{SO}_{4}+0.1 \mathrm{M} \mathrm{H}_{2} \mathrm{SO}_{4}$, taking into account that the same anion was present in all three cases. The catalytic effect was studied in $0.1 \mathrm{M} \mathrm{NaNO}_{3}+$ $+0.1 \mathrm{M} \mathrm{Na}_{2} \mathrm{SO}_{4}$ solution. Prior to each experiment, solutions were deaerated by nitrogen bubbling.

Cyclic voltammetric measurements and chronoamperometric studies were carried out in a conventional three-electrode electrochemical cell at a temperature of $T=298 \mathrm{~K}$. HOPG SPI-2 grade substrates (SPI Supplies, USA) were used as working electrodes, which were prepared by cleaving its surface with an adhesive tape immediately prior to each experiment. The electrode was held within a Teflon sheath with an exposed area of $0.216 \mathrm{~cm}^{2}$. The counter electrode was a Pt sheet $\left(1 \mathrm{~cm}^{2}\right)$, and the reference electrode was a saturated calomel electrode (SCE), ( $E_{S C E}=0.2415 \mathrm{~V} v \mathrm{~s}$. $\mathrm{SHE}$ ). All electrode potentials mentioned in this work are referred to this electrode. The experiments were performed with an EG\&G Princeton Applied Research model 273A potentiostat-galvanostat controlled by a microcomputer.

$\mathrm{Cu}$ nanoparticles prepared from different electrolytes by the potentiostatic step technique on HOPG substrates were characterized by SEM using a Zeiss MA 10 microscope integrated with an EDX analyzer.

\section{Results and discussion}

\section{Cyclic voltammetry}

Electrodeposition of $\mathrm{Cu}$ on the HOPG substrate was performed in the following plating solutions: a) $1 \mathrm{mM} \mathrm{CuSO}_{4}+0.1 \mathrm{M} \mathrm{Na}_{2} \mathrm{SO}_{4}(\mathrm{pH} 4.66)$, b) $1 \mathrm{mM} \mathrm{CuSO}_{4}+0.1 \mathrm{M} \mathrm{H}_{2} \mathrm{SO}_{4}(\mathrm{pH} \mathrm{0.95)}$, and c) $1 \mathrm{mM}$ $\mathrm{CuSO}_{4}+0.1 \mathrm{M} \mathrm{Na}_{2} \mathrm{SO}_{4}+0.1 \mathrm{M} \mathrm{H}_{2} \mathrm{SO}_{4}(\mathrm{pH}$ 1.10). The process was initially examined qualitatively by cyclic voltammetry recorded within the potential range $-0.7 \leq E / \mathrm{V} \leq 0.3$, at the scan rate $(\mathrm{d} E / \mathrm{d} t)$ of $10 \mathrm{mV} \mathrm{s}^{-1}$. As shown in Figure 1, the voltammetric responses of HOPG in three solutions exhibited similar features, including the hysteresis loop (the so-called nucleation loop) formed between cathodic and anodic sweep curves at negative potentials values, which is typical of a nucleation and growth process [21,22]. An extensive analysis of cyclic voltammograms at different scan rates confirming this conclusion was shown elsewhere [23]. During the potential scan towards the negative direction, a cathodic peak is observed, associated with the reduction of $\mathrm{Cu}^{2+}$ ions to $\mathrm{Cu}^{0}$. In the reverse scan, a single anodic peak is evidenced, consistent with the dissolution of Cu clusters deposited previously.

Generally, a single cathodic peak is evidenced as a result of the $\mathrm{Cu}^{2+}$ electroreduction process, and it is accepted that it occurs on a global stage via 2 electrons. However, it is well known that in an acid medium [24,25] or in the presence of complexing anions such as chloride [26], the electrodeposition of Cu can be considered to occur in two consecutive stages with the formation of $\mathrm{Cu}^{+}$ions as intermediate species. These stages can be described by equations (1) and (2)

$$
\begin{aligned}
& \mathrm{Cu}^{2+}+\mathrm{e}^{-}=\mathrm{Cu}^{+} \\
& \mathrm{Cu}^{+}+\mathrm{e}^{-}=\mathrm{Cu}^{0}
\end{aligned}
$$

with the first reaction being the rate-determining step. In fact, in the case of the electrolyte containing only sulphuric acid, the broad $\mathrm{Cu}^{2+}$ reduction peak could be considered to be formed by two waves, which could be associated with two steps of the process. 


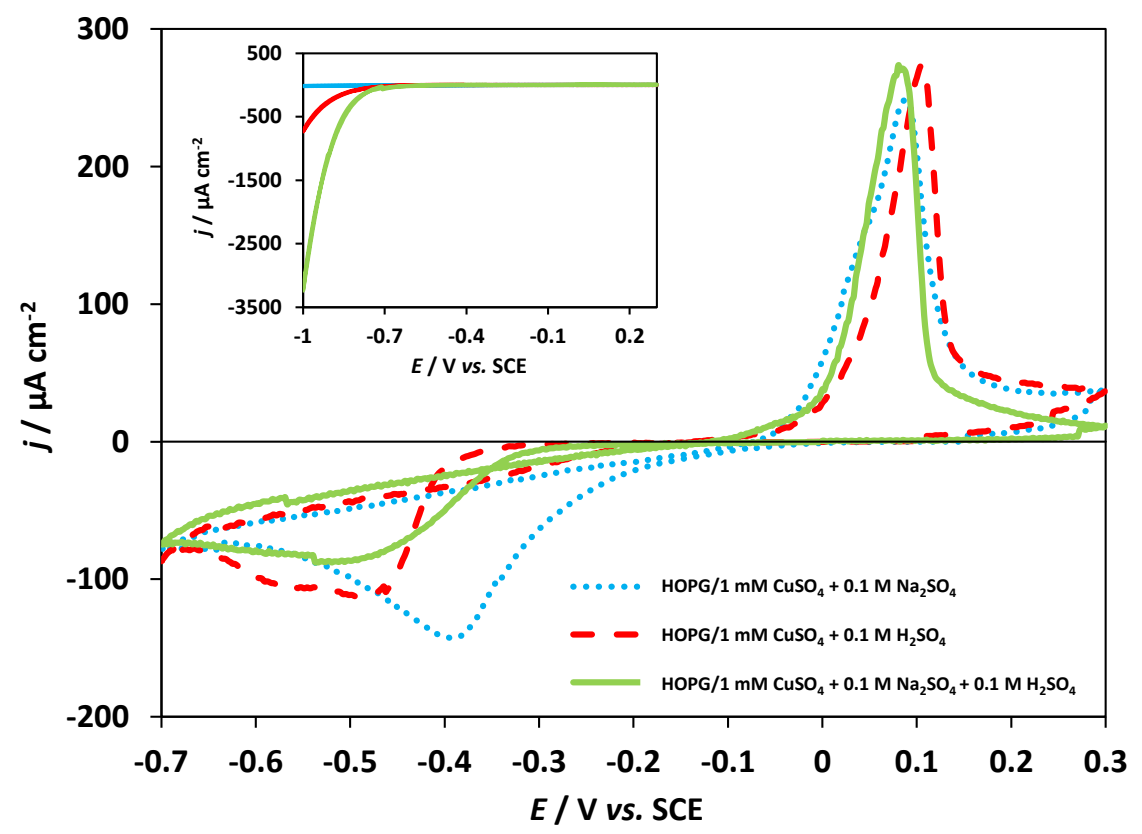

Figure 1. Cyclic voltammetry of $\mathrm{HOPG}$ for $1 \mathrm{mM} \mathrm{CuSO}_{4}$ in $0.1 \mathrm{M} \mathrm{Na}_{2} \mathrm{SO}_{4}, 0.1 \mathrm{M} \mathrm{H}_{2} \mathrm{SO}_{4}$ and $0.1 \mathrm{M} \mathrm{Na}_{2} \mathrm{SO}_{4}+$ $0.1 \mathrm{M} \mathrm{H}_{2} \mathrm{SO}_{4} \cdot \mid \mathrm{dE} / \mathrm{dt} /=10 \mathrm{mV} \mathrm{s}^{-1}$. Inset: cyclic voltammograms of HOPG in blank electrolyte solutions

For comparison, cyclic voltammograms of HOPG electrode immersed in blank solutions (without containing $\mathrm{Cu}(\mathrm{II})$ ions) shown in the inset of Figure 1, indicate that the hydrogen evolution reaction occurs at more negative potential values and does not interfere with the $\mathrm{Cu}$ electrodeposition process under the conditions considered in this study.

When the supporting electrolyte is $\mathrm{Na}_{2} \mathrm{SO}_{4}$ (solution a), which is added to the plating bath primarily to increase electrolyte conductivity, the peak corresponding to the reduction of $\mathrm{Cu}^{2+}$ ions, is occurring at a more positive potential value $\left(E_{\text {peak }}=-0.39 \mathrm{~V}\right)$ than in the other two cases, and reaching the maximum current density value of $j_{\text {peak }}=-142.68 \mu \mathrm{A} \mathrm{cm}{ }^{-2}$. The presence of $\mathrm{H}_{2} \mathrm{SO}_{4}$ in the plating solution (solution $\mathrm{b}$ ) also favors the conductivity of the electrolyte, showing $E_{\text {peak }}$ and $j_{\text {peak }}$ at $-0.49 \mathrm{~V}$ and $-112.68 \mu \mathrm{A} \mathrm{cm}{ }^{-2}$, respectively. According to the observed behavior, it could be inferred that part of $\mathrm{SO}_{4}{ }^{2-}$ ions can be adsorbed on the surface of HOPG substrate, reducing thus the number of active sites for the formation of Cu nuclei, in agreement with the literature reviewed [19,20]. Moreover, Hope and Woods [27] have demonstrated by in-situ surface-enhanced Raman scattering (SERS) that sulphate adsorption occurs during metal electrodeposition. Their spectro-electrochemical investigations revealed that sulphate ions were transient adsorbed species during $\mathrm{Cu}$ electrodeposition process, which was not observed for copper surfaces in the absence of metal ions in solution. For the third solution studied (solution c), although the conductivity was higher than of other supporting electrolytes, the most negative $E_{\text {peak }}$ for $C u$ deposition and the lowest $j_{\text {peak }}$ values were obtained. The copper nucleation is retarded by this plating solution which provides more sulphate anions at the electrode interface, and consequently, it can be assumed that they could be adsorbed on the surface, blocking more sites for Cu deposition.

The values of $E_{\text {peak }}$ and $j_{\text {peak }}$ for three studied electrolyte solutions are summarized in Table 1.

Table 1. Cathodic peak potentials and peak current densities for Cu deposition from three supporting electrolytes containing $1 \mathrm{mM} \mathrm{CuSO}_{4}$

\begin{tabular}{cccc}
\hline Supporting electrolyte & $0.1 \mathrm{M} \mathrm{Na}_{2} \mathrm{SO}_{4}$ & $0.1 \mathrm{M} \mathrm{H}_{2} \mathrm{SO}_{4}$ & $0.1 \mathrm{M} \mathrm{Na}_{2} \mathrm{SO}_{4}+0.1 \mathrm{M} \mathrm{H}_{2} \mathrm{SO}_{4}$ \\
\hline$E_{\text {peak }} / \mathrm{V}$ & -0.389 & -0.494 & -0.519 \\
\hline$j_{\text {peak }} / \mu \mathrm{A} \mathrm{cm}{ }^{-2}$ & -142.68 & -112.68 & -87.88 \\
\hline
\end{tabular}




\section{Chronoamperometry}

Potentiostatic current transients were carried out to obtain information about the kinetics of copper electrodeposition on the carbonaceous substrate. Representative $j$ - $t$ curves were performed applying simple potentiostatic pulses at selected potentials more negative than the cathodic peak potential (see Figure 1) for three cases studied, and they are shown in Figure 2 (inset graphics). These curves exhibit a typical shape of the nucleation process with 3D growth controlled by diffusion of electroactive species [28]. The potentiostatic current transients for three plating solutions showed an increase of current up to maximum, corresponding to the formation of Cu crystallites through the nucleation and growth process, followed by a decreasing region, reflecting the transition to linear diffusion. These results revealed that the presence of sodium sulfate in the plating solution generates the highest current for nucleus formation, which was reached at shorter times.

To analyze the type of nucleation, a commonly used criterion is the application of the theoretical model proposed by Sharifker and Hills [28]. By means of this model, two limiting nucleation mechanisms, instantaneous and progressive, can be distinguished based on the equations (3) and (4):

$$
\begin{aligned}
& \frac{j^{2}}{j_{\mathrm{m}}{ }^{2}}=\frac{1.9542}{\frac{t}{t_{\mathrm{m}}}}\left\{1-\exp \left[-1.2564\left(\frac{t}{t_{\mathrm{m}}}\right)\right]\right\}^{2} \\
& \frac{j^{2}}{j_{\mathrm{m}}{ }^{2}}=\frac{1.2254}{\frac{t}{t_{\mathrm{m}}}}\left\{1-\exp \left[-2.3367\left(\frac{t}{t_{\mathrm{m}}}\right)^{2}\right]\right\}^{2}
\end{aligned}
$$

where the parameters $j_{\mathrm{m}}$ and $t_{\mathrm{m}}$ are the maximum current density of the transient and the time at which the current maximum occurs, respectively.

Eq. (3) corresponds to the instantaneous nucleation where the nuclei are formed and grown on active sites of the carbonaceous substrate, all activated simultaneously. In contrast, Eq. (4) corresponds to the progressive nucleation where the nuclei are formed on preferential sites and activated at different times during the electroreduction process.

As shown in Figure 2, representative potentiostatic current transient data were normalized and compared with both types of the described model. As stated above, the corresponding experimental transients are those included in the inset of the figures from which the type of nucleation is analyzed.

Figure 2a shows a very good correlation for the transient obtained at $E=-0.42 \mathrm{~V}$ in solution $\mathrm{a}$, with the theoretical curve for progressive nucleation. For solution $b$, shown in Figure $2 b$, copper crystallites were generated at $E=-0.50 \mathrm{~V}$. Cu nucleation begins in a progressive way at short times, passing to an intermediate state until reaching instantaneous nucleation in the last stage. These results are in agreement with those obtained by Huang et al. [29]. They demonstrated that for copper deposition on HOPG electrode from $1 \mathrm{mM} \mathrm{CuSO}_{4}+1 \mathrm{M} \mathrm{H}_{2} \mathrm{SO}_{4}$ solution, the analysis of experimental transients according to the theoretical model proposed by Sharifker and Hills [28] showed a good correlation with the theoretical curve for progressive nucleation for a potential more negative than the reduction peak. At the last stage, nucleation transition from progressive to instantaneous was found at even more negative potential.

When the experiments were performed using the solution c, i.e., cupric sulfate with sodium sulfate and sulfuric acid solution as supporting electrolyte (Figure $2 \mathrm{c}$ ), the nucleation mode follows predominately progressive nucleation, which is a behavior similar to that of the first electrolytic medium $\left(0.1 \mathrm{M} \mathrm{Na}_{2} \mathrm{SO}_{4}\right)$. In this case, the deposits were formed at $E=-0.55 \mathrm{~V}$. 

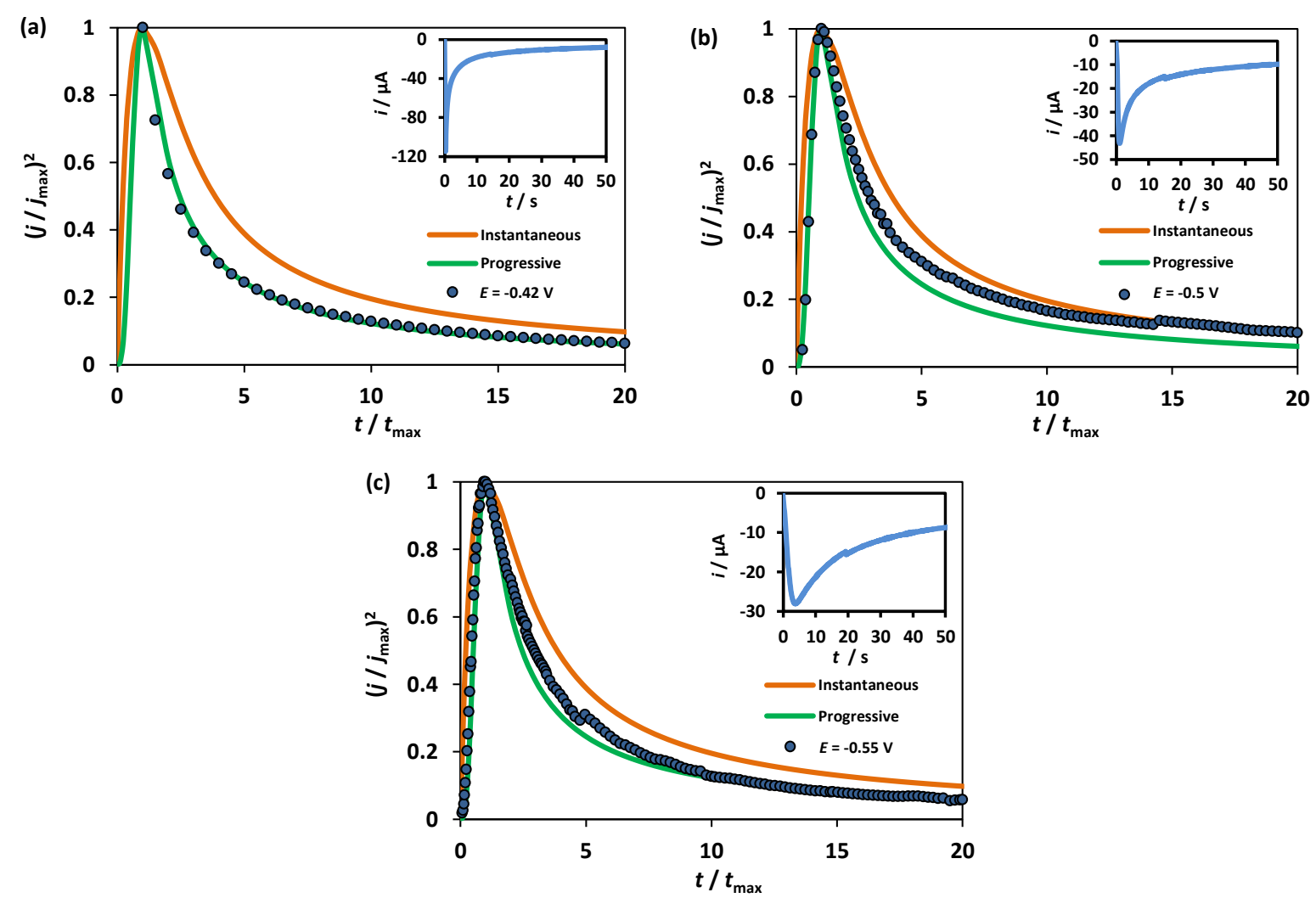

Figure 2. Non-dimensional $\left(\mathrm{j} / \mathrm{j}_{\max }\right)^{2} \mathrm{vs}$. $\left(\mathrm{t} / \mathrm{t}_{\max }\right)$ plots of experimental current transients (shown in insets) for HOPG in solution containing $1 \mathrm{mM} \mathrm{CuSO}_{4}$ and: (a) $0.1 \mathrm{M} \mathrm{Na}_{2} \mathrm{SO}_{4}$; (b) $0.1 \mathrm{M} \mathrm{H}_{2} \mathrm{SO}_{4}$;

(c) $0.1 \mathrm{M} \mathrm{Na}_{2} \mathrm{SO}_{4}+0.1 \mathrm{M} \mathrm{H}_{2} \mathrm{SO}_{4}$

\section{Surface analysis}

Direct information on the shape, size and density of Cu nanoparticles can be acquired by scanning electron microscopy (SEM) analysis. Figure 3 exhibits hemispheric Cu deposits generated by a simple potentiostatic pulse on HOPG substrate in three analyzed solutions.
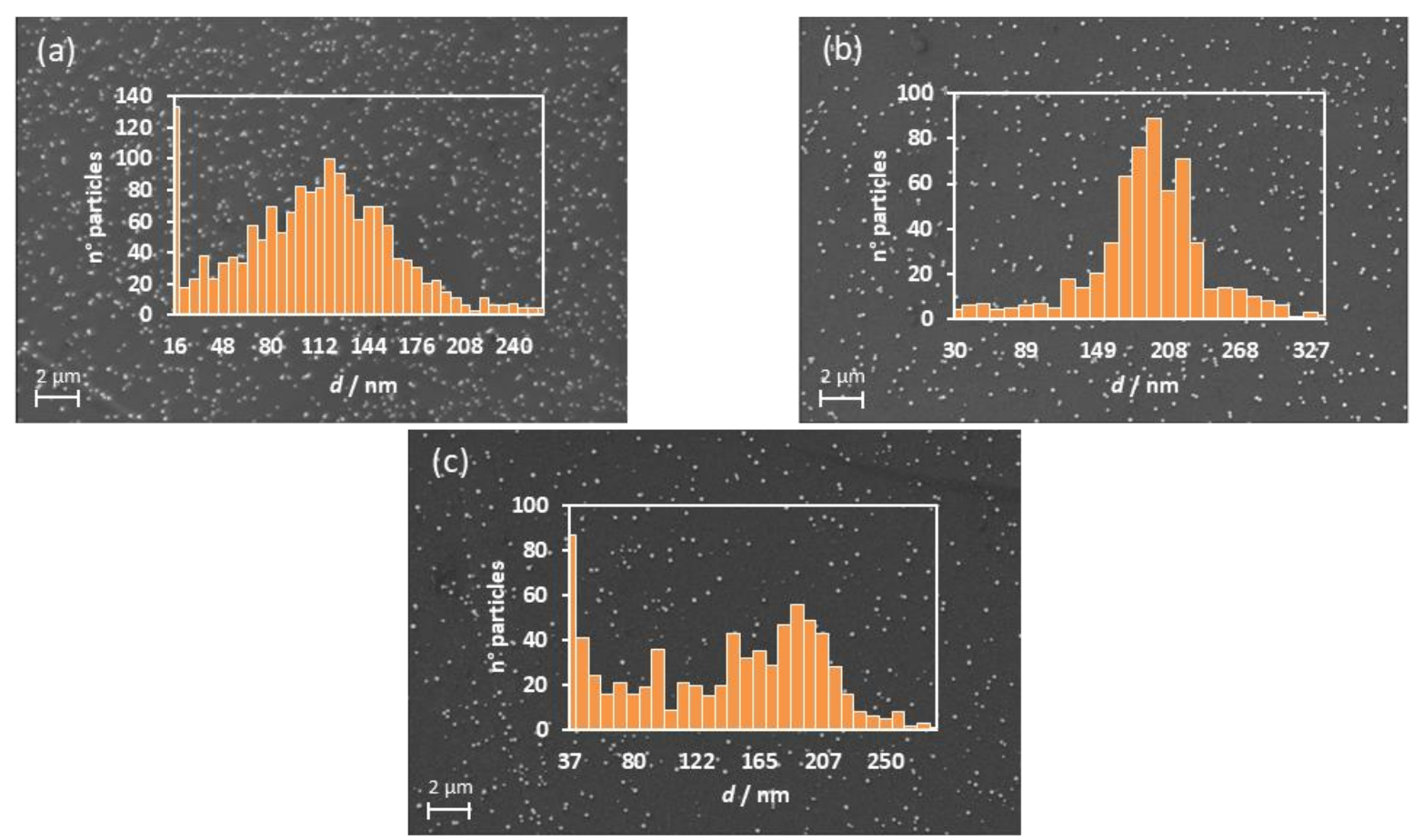

Figure 3. SEM images of CuNPs electrodeposited on HOPG from $1 \mathrm{mMCuSO}_{4}$ in: (a) $0.1 \mathrm{M} \mathrm{Na}_{2} \mathrm{SO}_{4}$, (b) $0.1 \mathrm{M}$ $\mathrm{H}_{2} \mathrm{SO}_{4}$ and (c) $0.1 \mathrm{M} \mathrm{Na}_{2} \mathrm{SO}_{4}+0.1 \mathrm{M} \mathrm{H}_{2} \mathrm{SO}_{4}$, and corresponding particle size distribution histograms 
Figure 3a reveals the formation of a considerable density of $\mathrm{Cu}$ particles distributed on the HOPG surface when $\mathrm{Na}_{2} \mathrm{SO}_{4}$ was used as the supporting electrolyte (solution a). These particles were electrodeposited at $E=-0.42 \mathrm{~V}$ during $100 \mathrm{~s}$. Cu structures present different particle sizes (as shown in the corresponding histogram), consistent with progressive nucleation. A large number of small particles can be observed in Figure 3a, with a minimum diameter of $16 \mathrm{~nm}$, and large ones with a maximal diameter of $259.17 \mathrm{~nm}$. Figure $3 \mathrm{~b}$ shows copper particles obtained by electrodeposition at $-0.5 \mathrm{~V}$ during $120 \mathrm{~s}$ in the copper solution containing $\mathrm{H}_{2} \mathrm{SO}_{4}$ (solution b). The particle size dispersion is slightly smaller, resulting in the formation of larger copper particles with a maximum diameter value around $339 \mathrm{~nm}$ and without the predominance of small particles. Therefore, the particle size distribution tends to conform to the normal distribution, with crystals mostly between $180-210 \mathrm{~nm}$ in diameter.

Some of the $\mathrm{Cu}$ nuclei formed in solution $\mathrm{b}$ are formed on HOPG step edges acting as active sites for metal nucleation, and the presence of crystals forming dimers and trimers are also detected, as shown in Figure 4.

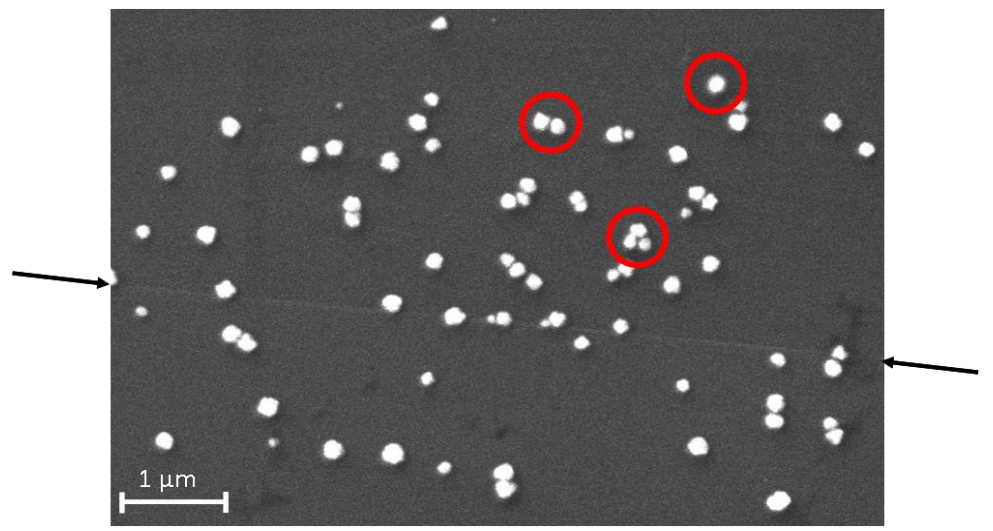

Figure 4. SEM image of CUNPs electrodeposited from $1 \mathrm{mM} \mathrm{CUSO}_{4}+0.1 \mathrm{M} \mathrm{H}_{2} \mathrm{SO}_{4}$ showing deposits on HOPG step edges and presence of single particles, dimers and trimers

As seen in Figure 3c, the number of metallic clusters generated at $E=-0.55 \mathrm{~V}$ during $120 \mathrm{~s}$ in the combined electrolyte (solution c) decreases, and a wide range of particle sizes is observed with small particles of $37 \mathrm{~nm}$ and larger with a maximum diameter of $300 \mathrm{~nm}$. These crystals grow on random active sites and also on some HOPG step edges.

Generally, SEM images confirmed the progressive nature of copper nucleation derived by the Sharifker and Hills dimensionless analysis for three solutions used.

Figure 5 exhibits SEM images of Cu crystallites formed on the HOPG electrode with marked points where the EDX analysis was performed. Cu structures were generated on the surface substrate after applying a potential pulse at $E=-0.5 \mathrm{~V}$ for $120 \mathrm{~s}$ in the solution containing $\mathrm{H}_{2} \mathrm{SO}_{4}$.
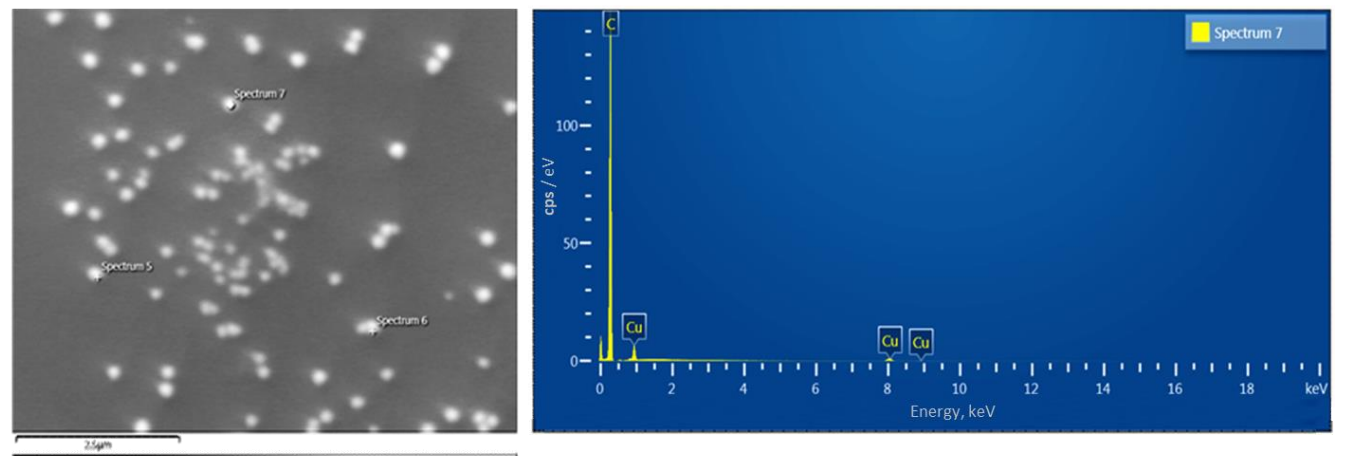

Figure 5. SEM micrograph of HOPG substrate after Cu deposition from $1 \mathrm{mM} \mathrm{CuSO}_{4}+0.1 \mathrm{M}$ $\mathrm{H}_{2} \mathrm{SO}_{4}$ solution at $-0.5 \mathrm{~V}$ for $120 \mathrm{~s}$ and representative EDX analysis applied on top of crystallite 
Only the elemental distribution for the most representative point is shown, confirming the presence of $\mathrm{Cu}$ besides the signal corresponding to the $\mathrm{C}$ substrate (HOPG).

\section{Electrocatalysis}

The catalytic activity of CuNPs modified HOPG substrates was evaluated qualitatively by cyclic voltammetry in $0.1 \mathrm{M} \mathrm{NaNO}_{3}+0.1 \mathrm{M} \mathrm{Na}_{2} \mathrm{SO}_{4}$ solution. Initially, Cu nanoparticles were obtained on the HOPG electrode after applying a single potentiostatic pulse to the electrode immersed in three electrolytes studied at $E=-0.65 \vee$ for $400 \mathrm{~s}$. Potentiostatic pulse parameters, different from those applied for nucleation analysis, were chosen, i.e., a more negative pulse potential and a longer deposition time, to increase the copper-covered area on the HOPG electrode surface, and therefore, to induce more noticeable nitrate anion reduction signal in the voltammetric analysis.

The type of nucleation, in this case, was analyzed anew, as well as the surface characterization by SEM of CUNPs modified HOPG electrode.

Figure 6a show a representative SEM image and the corresponding size distribution of Cu deposits generated when $\mathrm{Na}_{2} \mathrm{SO}_{4}$ (solution a) was used as the supporting electrolyte.
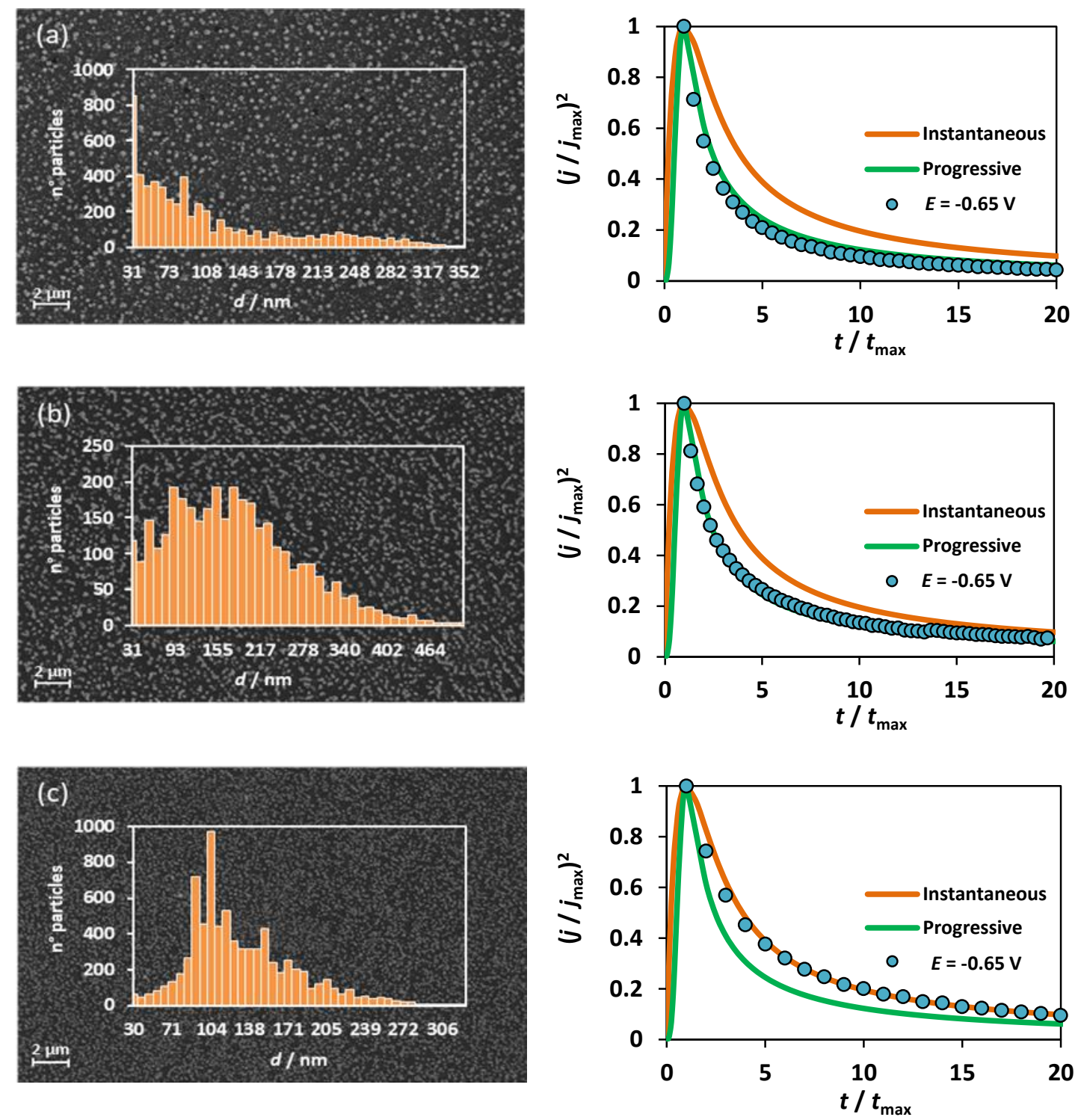

Figure 6. SEM images of CuNPs electrodeposited from $1 \mathrm{mM} \mathrm{CuSO}_{4}$ in (a) $0.1 \mathrm{M} \mathrm{Na}_{2} \mathrm{SO}_{4}$, (b) $0.1 \mathrm{M} \mathrm{H}_{2} \mathrm{SO}_{4}$ and (c) $0.1 \mathrm{M} \mathrm{Na}_{2} \mathrm{SO}_{4}+0.1 \mathrm{M} \mathrm{H}_{2} \mathrm{SO}_{4}$, with the corresponding particle size distribution histograms (left), and nondimensional $\left(\mathrm{j} / \mathrm{j}_{\max }\right)^{2}$ vs. $\left(\mathrm{t} / \mathrm{t}_{\max }\right)$ plots of experimental current transients (right) 
Crystals of different sizes with a predominance of very small particles of the order of 31-50 nm with maximum diameters of $352 \mathrm{~nm}$, are observed. The covered area was $17 \%$ of the electrode geometric area, calculated from the average of several low magnification SEM images. The type of nucleation analyzed from Sharifker and Hills model leads to a progressive nucleation mode, the same as for $E=-$ $0.42 \mathrm{~V}$. For the second solution containing $\mathrm{H}_{2} \mathrm{SO}_{4}$ (solution b), Figure $6 \mathrm{~b}$ shows a representative SEM image of Cu-decorated HOPG electrode revealing a great disparity in copper particle sizes as a result of the formation of many agglomerates that reached values up to $514 \mathrm{~nm}$, but also a large number of crystallites between $30-50 \mathrm{~nm}$. The covered area of $22 \%$ was estimated. Size diversity of metal deposits is consistent with a progressive nucleation and growth mechanism, which was corroborated throughout the analyzed time range by the theoretical model used. The same nucleation model was obtained previously for $E=-0.50 \mathrm{~V}$ at short times. When the deposits were formed using the third solution (solution c), a large number of deposits with a diameter of approximately $104 \mathrm{~nm}$ is observed, some of them reaching a maximum size of $326 \mathrm{~nm}$, with no predominance of particles with diameters less than $50 \mathrm{~nm}$ (Figure 6c). In this case, the calculated covered area was $24 \%$ and, unlike for the pulse at $E=-0.55 \mathrm{~V}$, the nucleation is predominantly instantaneous.

\section{Electrocatalytic properties of CuNPs}

After this analysis, the electrocatalytic behavior of CuNPs modified HOPG electrode was evaluated for the nitrate reduction reaction. Figure 7 shows the voltammetric results for different $\mathrm{Cu}$ structures generated from three plating electrolytes and recorded in the solution of $0.1 \mathrm{M} \mathrm{NaNO}_{3}$ $+0.1 \mathrm{M} \mathrm{Na}_{2} \mathrm{SO}_{4}$. Cathodic current peaks observed in the range $-0.40 \leq E / \mathrm{V} \leq-0.55$, were attributed to the reduction reaction of nitrate ions, while the current increase evidenced at more negative potential values is related to the hydrogen evolution reaction. The voltammetric response for a solid copper electrode in the same solution containing nitrate ions is also shown in Figure 7 for comparison purposes.

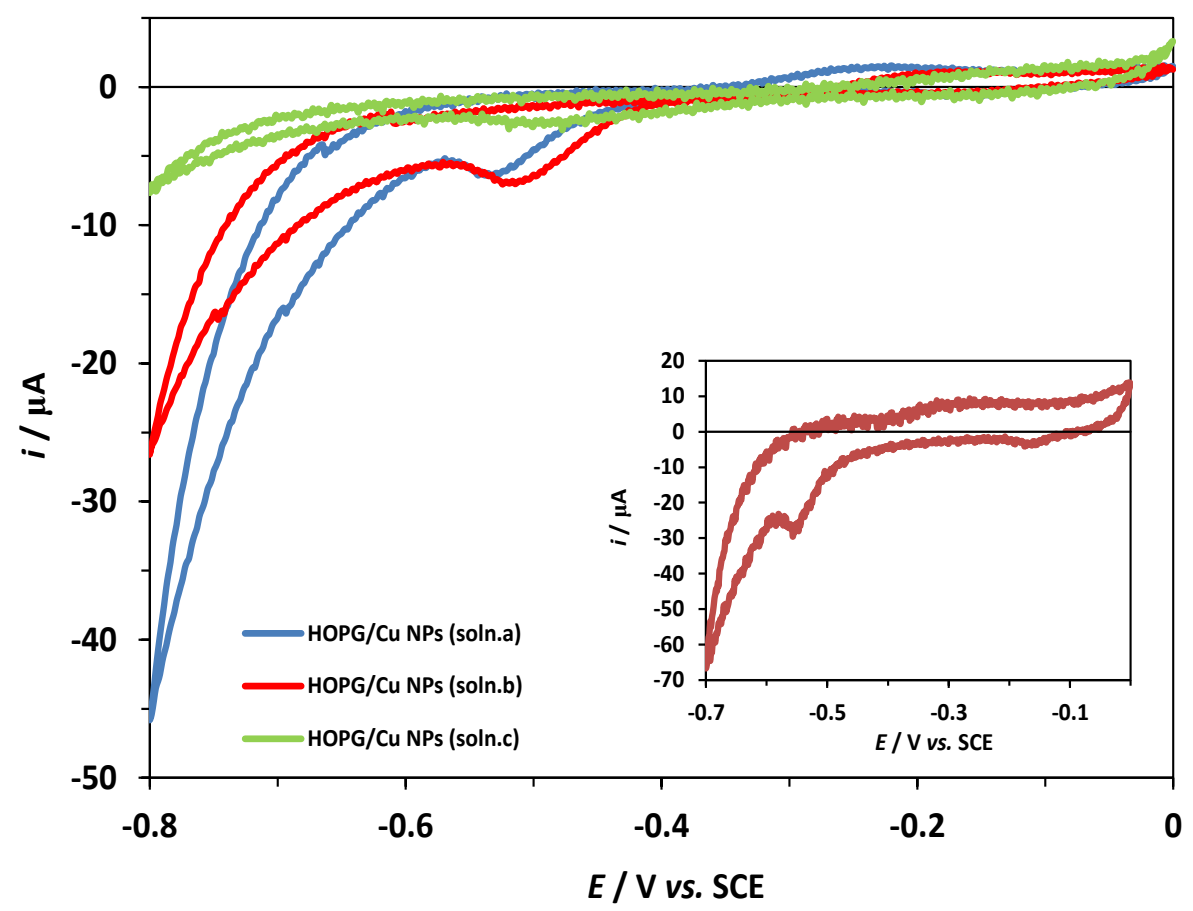

Figure 7. Cyclic voltammograms of CUNPs electrodeposited on HOPG electrode from three plating solutions and recorded in $0.1 \mathrm{M} \mathrm{NaNO}_{3}+0.1 \mathrm{M} \mathrm{Na}_{2} \mathrm{SO}_{4}$. Inset: $\mathrm{CV}$ of polycrystalline $\mathrm{Cu}$ recorded in the same solution. $/ \mathrm{dE} / \mathrm{dt} /=10 \mathrm{mV} \mathrm{s}^{-1}$ 
The HOPG-modified electrodes showed voltammetric features similar to those of polycrystalline copper, i.e., a cathodic peak corresponding to nitrate reduction in the same potential region $(-0.45<E / \mathrm{V}<0.6)$, followed by an abrupt current increase due to hydrogen evolution. The HOPG electrodes modified by copper crystals prepared from solutions containing $\mathrm{H}_{2} \mathrm{SO}_{4}$ and $\mathrm{Na}_{2} \mathrm{SO}_{4}$ showed a more pronounced catalytic effect than the one observed for the solution containing both components. It can be inferred that this enhancement of the electrocatalytic effect, is due to the presence of a larger number of crystallites smaller than $50 \mathrm{~nm}$, which favor adsorption of nitrate ions, despite the fact that a larger covered area was found for the third solution. This behavior is in accordance with the findings of other authors [30,31]. A. J. Wain [30] reported that the electrocatalytic activity was increased with decreasing particle size in the range 5-50 nm, which was attributed to the exposure of different reactive facets of the crystallites. Also, Masel et al. [31] demonstrated that $\mathrm{Ag}$ nanoparticles increased their electrocatalytic activity with decreasing particle size until a certain particle size $(5 \mathrm{~nm})$. They also indicated that this behavior could be caused by several reasons, such as variations with a particle size of the number of steps or kink sites of the crystallites, the electronic structure or work function of the particles, or the binding energy of the involved species. Accordingly, the aforementioned assumption is not conclusive and related studies in this regard are in progress.

Table 2 summarizes the values of the peak potential and maximum cathodic current values for nitrate reduction reaction using CuNPs deposited on HOPG surfaces from three supporting electrolyte solutions. The values corresponding to a freshly polished polycrystalline copper electrode were also included.

Table 2. Cathodic peak potential and maximum cathodic current values of nitrate reduction at CuNPs deposited from different supporting electrolytes

\begin{tabular}{ccc}
\hline \multirow{2}{*}{ Supporting electrolyte for CuNPs } & \multicolumn{2}{c}{ Nitrate reduction } \\
\cline { 2 - 3 } & $E_{\text {peak }} / \mathrm{V}$ & $i_{\max } / \mu \mathrm{A}$ \\
\hline $\mathrm{Na}_{2} \mathrm{SO}_{4}$ & -0.54 & 6.39 \\
\hline $\mathrm{H}_{2} \mathrm{SO}_{4}$ & -0.52 & 7.04 \\
\hline $\mathrm{Na}_{2} \mathrm{SO}_{4}+\mathrm{H}_{2} \mathrm{SO}_{4}$ & -0.48 & 3.12 \\
\hline Solid copper & -0.56 & 29.50 \\
\hline
\end{tabular}

\section{Conclusions}

Formation of HOPG supported copper nanoparticles (CUNPs) by electrodeposition from three different supporting electrolytes containing sulphate anions, and their potential application as electrocatalyst materials for the reduction reaction of nitrate ions were analyzed.

Cyclic voltammetric results indicated that for all supporting electrolyte solutions, the kinetics of the nucleation and growth of CuNPs on HOPG electrodes follows predominately a progressive model, presenting a good correlation with SEM images.

The voltammetric response of CuNPs modified HOPG electrode regarding nitrate reduction showed a better catalytic effect for $\mathrm{Cu}$ nanoparticles generated from solutions containing either $\mathrm{Na}_{2} \mathrm{SO}_{4}$ or $\mathrm{H}_{2} \mathrm{SO}_{4}$ species.

Acknowledgements: The authors wish to thank the Universidad Nacional del Sur (Argentina) for the financial support of this work. N. Zurita acknowledges a fellowship granted by CIC (Comisión de Investigaciones Científicas de la Prov. de Buenos Aires). 


\section{References}

[1] S. Magdassi, M. Grouchko, A. Kamyshny, Materials (Basel) 3(9) (2010) 4626-4638. https://doi.org/10.3390/ma3094626

[2] Z. Qing, A. Bai, S. Xing, Z. Zou, X. He, K. Wang, R. Yang, Biosensors and Bioelectronics 137 (2019) 96-109. https://doi.org/10.1016/i.bios.2019.05.014

[3] Y. Zhang, N. Li, Y. Xiang, D. Wang, P. Zhang, Y. Wang, S. Lu, R. Xu, J. Zhao, Carbon 156 (2020) 506-513. https://doi.org/10.1016/i.carbon.2019.10.006

[4] D.-D. Wang, C.-W. Ge, G.-A. Wu, Z.-P. Li, J.-Z. Wang, T.-F. Zhang, Y.-Q. Yu, L.-B. Luo, Journal of Materials Chemistry C 5 (2017) 1328-1335. https://doi.org/10.1039/c6tc05117k

[5] M. del C. Aguirre, S. E. Urreta, C. G. Gomez, Sensors and Actuators B 284 (2019) 675-683. https://doi.org/10.1016/i.snb.2018.12.124

[6] S. B. Khan, F. Ali, K. Akhtar, Carbohydrate Polymers 207 (2019) 650-662. https://doi.org/10.1016/i.carbpol.2018.12.032

[7] R. Suresh Babu, P. Prabhu, S. Sriman Narayanan, Materials Today: Proceedings 36(4) (2019) 867-872. https://doi.org/10.1016/j.matpr.2020.07.020

[8] E. M. Bakhsh, F. Ali, S. B. Khan, H. M. Marwani, E. Y. Danish, A. M. Asiri, International Journal of Biological Macromolecules 131 (2019) 666-675.

https://doi.org/10.1016/j.ijbiomac.2019.03.095

[9] World Health Organization, Guidelines for Drinking-water Quality, 3rd Edition, 2004. https://www.who.int/water sanitation health/dwq/GDWQ2004web.pdf

[10] C. Sun, F. Li, H. An, Z. Li, A. M. Bond, J. Zhang, Electrochimica Acta 269 (2018) 733-741. https://doi.org/10.1016/i.electacta.2018.03.005

[11] A. M. Stortini, L. M. Moretto, A. Mardegan, M. Ongaro, P. Ugo, Sensors and Actuators B 207 Part A (2015) 186-192. https://doi.org/10.1016/i.snb.2014.09.109

[12] M. R. Majidi, K. Asadpour-Zeynali, B. Hafezi, International Journal of Electrochemical Science 6 (2011) 162-170. http://www.electrochemsci.org/papers/vol6/6010162.pdf

[13] D. Reyter, M. Odziemkowski, D. Bélanger, L. Roué, Journal of the Electrochemical Society 154(8) (2007) K36. https://doi.org/10.1149/1.2746805

[14] Y. Li, J.Z. Sun, C. Bian, J. H. Tong, H. P. Dong, H. Zhang, S. H. Xia, AIP Advances 5(4) (2015) 041312. https://doi.org/10.1063/1.4905712

[15] Y.-J. Shih, Z.-L. Wu, C.-Y. Lin, Y.-H. Huang, C.-P. Huang, Applied Catalysis B 273 (2020) 119053. https://doi.org/10.1016/j.apcatb.2020.119053

[17] D. Grujicic, B. Pesic, Electrochimica Acta 50(22) (2005) 4426-4443. https://doi.org/10.1016/j.electacta.2005.02.012

[18] D. Grujicic, B. Pesic, Electrochimica Acta 47(18) (2002) 2901-2912. https://doi.org/10.1016/$\underline{\text { S0013-4686(02)00161-5 }}$

[19] J. Vazquez-Arenas, G. Vázquez, A. M. Meléndez, I. González, Journal of The Electrochemical Society 154(9) (2007) D473. https://doi.org/10.1149/1.2755873

[20] O. Ghodbane, L. Roué, D. Bélanger, Electrochimica Acta 52(12) (2007) 5843-5855. https://doi.org/10.1016/i.electacta.2007.03.009

[21] S. Fletcher, C. S. Halliday, D. Gates, M. Westcott, T. Lwin, G. Nelson, Journal of Electroanalytical Chemistry 159(2) (1983) 267-285. https://doi.org/10.1016/S00220728(83)80627-5

[22] V. A. Isaev, O. V. Grishenkova, Y. P. Zaykov, Journal of Solid State Electrochemistry 22 (2018) 2775-2778. https://doi.org/10.1007/s10008-018-3989-9

[23] N. Zurita, S. G. García, Avances en Ciencias e Ingeneria 11 (2020) Art. 3. https://www.executivebs.org/publishing.cl/avances-en-ciencias-e-ingenieria-vol-11-nro-1ano-2020-articulo-3/\#aci2020vol11nro1 
[24] A. Milchev, T. Zapryanova, Electrochimica Acta 51(14) (2006) 2926-2933. https://doi.org/10.1016/i.electacta.2005.08.045

[25] T. Zapryanova, A. Hrussanova, A. Milchev, Journal of Electroanalytical Chemistry 600(2) (2007) 311-317. https://doi.org/10.1016/i.jelechem.2006.10.002

[26] G. Gunawardena, G. Hills, I. Montenegro, Journal of Electroanalytical Chemistry and Interfacial Electrochemistry 184(2) (1985) 357-369. https://doi.org/10.1016/00220728(82)85080-8

[27] G. A. Hope, R. Woods, Journal of the Electrochemical Society 151(9) (2004) C550. https://doi.org/10.1149/1.1774186

[28] B. Scharifker, D. Hills, Electrochimica Acta 28(7) (1982) 879-889. https://doi.org/10.1016/0013-4686(83)85163-9

[29] L. Huang, E.-S. Lee, K.-B. Kim, Colloids and Surfaces A 262(1-3) (2005) 125-131. https://doi.org/10.1016/i.colsurfa.2005.03.023

[30] A. J. Wain, Electrochimica Acta 92 (2013) 383-391. https://doi.org/10.1016/i.electacta.2013.01.074

[31] A. Salehi-Khojin, H.-R. M. Jhong, B. A. Rosen, W. Zhu, S. Ma, P. J. A. Kenis, R. I. Masel, Journal of Physical Chemistry C 117(4) (2013) 1627-1632. https://doi.org/10.1021/jp310509z

(C)2021 by the authors; licensee IAPC, Zagreb, Croatia. This article is an open-access article distributed under the terms and conditions of the Creative Commons Attribution license (https://creativecommons.org/licenses/by/4.0/) 